\title{
Forced Implementation of SFAS 108 on Islamic Insurance? An Interpretation Study of Gray and Sharia
}

\author{
Dodik Siswantoro $^{1 *}$ \\ ${ }^{1}$ Faculty of Economics and Business, Universitas Indonesia, Depok 16424, Indonesia \\ *dodik.siswantoro@ui.ac.id
}

\begin{abstract}
Financial Accounting Standard (FAS) No. 108 on Islamic Insurance, which has been effectively applied since 1 January 2010, has received many responses from related companies. Generally, they have not prepared for the standard. This is because extensive efforts are required for the implementation, for example, the separation of funds between shareholders and clients. The method used in the study follows the Gray approach, analysis of the interview results, and analysis of the non-parametric approach to look at the significance of differences. The previous standard did not specify in detail clients' funds, reserves, and income statement. In the case of Islamic insurance, any tabarru or premium earned must be able to cover probable claims; this is the basic difference between Islamic and conventional insurance.
\end{abstract}

Keywords: Insurance, Claim, Islam, Gray, Takaful.

\section{INTRODUCTION}

Initially, the Statement of Financial Accounting Standards (SFAS) was prepared by the drafting team based on a proposal from the relevant parties. Afterwards, a small team was arranged to review the basic concept before assessing and taking further revision. Thereafter, the SFAS may be used by parties or institutions related to such standards. In the implementation, however, problems may arise, such as unpreparedness, mismatch, or other issues. Therefore, it is necessary to prepare the infrastructure and system in the implementation of a standard in practice.

In the case of the preparation of standards for Islamic insurance, there is an interesting issue, as Islamic insurance differs in character from conventional insurance. Therefore, Islamic insurance requires special treatment. In this case, Islamic insurance practitioners are already aware of this. Furthermore, they also have to prepare for if it is finally applied. This alignment may be caused by the characteristic that in itself requires special treatment. However, this is not easy because not all Islamic insurances have the ability and expertise to meet the regulations established for Islamic insurance schemes.

\section{LITERATURE REVIEW AND HYPOTHESIS DEVELOPMENT}

Research on the influence of culture and nation developed significantly in the 1990s. The environment may have had an impact on accounting as a social science. The preliminary research on the influence of culture was conducted by Hofstede in $1980^{1}$ while further research development was conducted by Gray in 1988 as follows ${ }^{2,3}$.

... model by adding the elements of accounting values (AV) and accounting systems (AS) and their links to societal values (SV) and institutional consequences (IC). Gray posits that accountants' attitudes or value systems are related to and derived from societal values. Accounting values, in turn, affect accounting systems. Accounting systems are also influenced by institutional consequences, such as legal systems and capital markets, which in turn, are influenced by societal values.

Gray $^{2}$ adds an element of accounting values (AV) and accounting systems (AS) to the theory proposed by Hofstede. This affects other factors and components of the theory. Furthermore, the hypothesis proposed by Gray is as follows ${ }^{2,3}$

1. The higher a country ranks in terms of IND and the lower it ranks in terms of UA and PD, then the more likely it is to rank highly in terms of professionalism.

2. The higher a country ranks in terms of UA and PD and the lower it ranks in terms of IND, then the more likely it is to rank highly in terms of uniformity.

3. The higher a country ranks in terms of UA and the lower it ranks in terms of IND and MASC, then the more likely it is to rank highly in terms of conservatism.

4. The higher a country ranks in terms of UA and PD and the lower it ranks in terms of IND and MASC, then the 
more likely it is to rank highly in terms of secrecy.

Gray added some factors in the analysis, namely, professionalism, uniformity, conservatism, and secrecy. From the variables identified by Hofstede ${ }^{1}$, Gray ${ }^{2}$ conducted a combination and output, as demonstrated in Table 1.

Table.1. Variable Correlation between Hofstede and Gray ${ }^{3}$

\begin{tabular}{|c|c|c|c|c|}
\hline \multicolumn{4}{|c|}{ Hofstede } & Gray \\
\hline $\mathrm{IND} \uparrow$ & $\mathrm{UA} \downarrow$ & $\mathrm{PD} \downarrow$ & - & Professionalism $\uparrow$ \\
\hline $\mathrm{IND} \downarrow$ & $\mathrm{UA} \uparrow$ & $\mathrm{PD} \uparrow$ & - & Uniformity $\uparrow$ \\
\hline $\mathrm{IND} \downarrow$ & $\mathrm{UA} \uparrow$ & - & MASC $\downarrow$ & Conservatism $\uparrow$ \\
\hline IND $\downarrow$ & $\mathrm{UA} \uparrow$ & $\mathrm{PD} \uparrow$ & MASC $\downarrow$ & Secrecy $\uparrow$ \\
\hline
\end{tabular}

Table 1 shows that high individualism (IND) and masculinity (MASC) and low uncertainty avoidance (UA) and power distance (PD) are able to improve transparency (a low secrecy). In addition, the professionalism and uniformity factors are contradictive; meanwhile, the level of secrecy decreased by the power distance is conservatism. From the correlation of these variables, it can be concluded that there are structured patterns in the mapping theory made by Hofstede and the output of Gray.

The improvement implication of the revised model shows how other factors may affect the accounting, even though the religious element has not yet been added. This can be because religion does not play an important role in policy making and determination. Hofstede puts the religious element as a consequence of the institution (see Figure 1$)^{3}$. It appears that religion plays only a small role and is relatively on the same level as other factors.

However, in Islam, the term of the purpose of religion is broader than the accounting value. In Islam, the calculation and assessment issues of the assets associated with the payment of zakat must be conducted properly with reference to the necessary rule's requirements. Since zakat is a form of worship in Islam, it needs more special and careful attention due to its importance among other obligations.

If Islamic teaching is implemented, it will have implications for the activities in accordance with Islamic teaching. Therefore, problems that usually occur in the financial business and investments are not too misleading. This is because the accounting standards which refer to the calculation of zakat, which is universally accepted. This will certainly facilitate the accounting records of any Muslim. For a Muslim, the religious factor becomes the main issue that must be considered since it is a very important factor. Therefore, the model created by Gray could be modified to include the influence of religion (Figure 1).

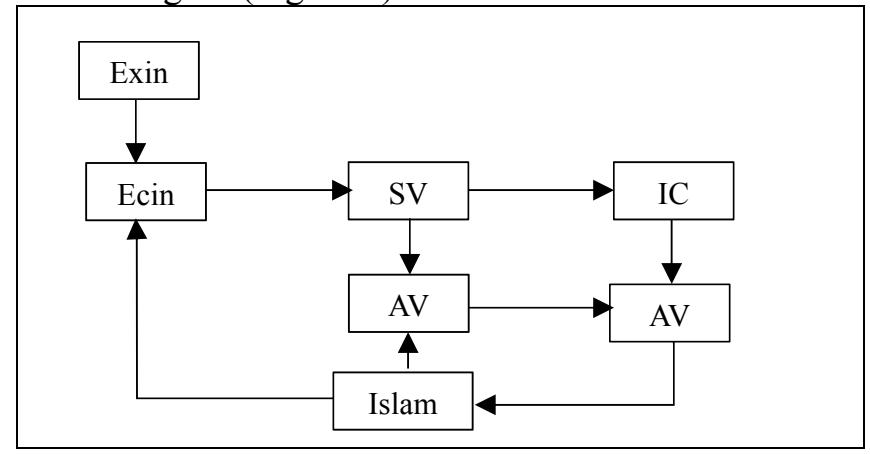

Figure.1. Modification of Gray Theory in the Context of Islam and Thought Influences ${ }^{3}$

Note: Exin: External influences; Ecin: Ecological influences

Figure 1 shows that Islamic principles and study factors for a Muslim may affect the value proposed by Hofstede and Gray. This is because sharia factors can play a dominant role in regulating every Muslim's activity. Islamic thinking and principles, if applied in real life, will have an effect on all aspects of life, especially business, finance, and, of course, accounting; afterward, it will be internalized in the other activities.

Doupnik \& Tsakumis ${ }^{3}$ evaluated Hofstede's approach. At the national level, the results of several studies are quite similar and significant, such as research conducted by Sudarwan and Fogarty ${ }^{4}$. Regarding the secrecy issue, Zarzeski ${ }^{5}$ supported the hypothesis proposed by Gray. Furthermore, according to Jaggi and Low ${ }^{6}$, culture does not have an impact on a nation's laws, meaning that the culture is merely casuistic and local.

Furthermore, the research on the Hofstede individual scale is conducted to examine the theory of Doupnik and Richter $^{7}$, except for how the factor of masculinity related to uniformity, which is investigated by Roberts and Salter ${ }^{8}$. In addition, several studies, such as by Chanchani and McGregor ${ }^{9}$ and $\mathrm{Smith}^{10}$, support the theory proposed by Hofstede. However, Novaresh ${ }^{11}$ argued that the theory proposed by Hofstede is not appropriate for Iran due to the change in the government system, which is still relatively new. With a similar pattern, this can occur in Indonesia, such as in the research conducted by Sudarwan and Fogarty ${ }^{4}$.

In Islam, studies and principles are rooted in the Qur'an and Sunnah. Despite the influence of schools in each 
region or country, the difference is not very great. Therefore, the linkage with the culture is relatively equal. However, the adjustment to the needs and interests can also change the existing pattern or form.

This paper discusses Takaful (Islamic insurance). The Takaful industry requires a global similarity regarding the regulations and laws ${ }^{12}$. The accounting standards made by the Accounting and Auditing Organization for Islamic Financial Institutions (AAOFI) at least give general directions on accounting treatment. In addition, the International Financial Reporting Standard (IFRS) has not regulated this issue, which, if it were done, could make it more complex ${ }^{13}$. In the case of Indonesia, the hypothesis may concern the difference between the secrecy issue in Indonesia and that of other countries adopting Islamic accounting standards. Indonesia has a high level of secrecy compared to other countries. The hypothesis is as follows:

\section{H1: There is a difference in the secrecy issue for Indonesia compared to other countries adopting Islamic accounting standards.}

\section{Classical Issues}

In the financial statement of insurance, specifically the income statement did not disclose accurate and precise figures because of the incompleteness of the data and the income criteria from accountants and the auditor. This means the standard of income recognition for each insurance has a different basis. Another debatable issue is the cost of acquisition, reserve, and accident and health insurance ${ }^{14}$, as well as non-admitted assets ${ }^{15}$.

Anderson ${ }^{15}$ identified that insurance companies in general do not comply with the accounting standards. $\mathrm{He}$ showed that the growth of the company, policies, investments, and returns are likely to change depending on the change in accounting methods. In this case, the insurance companies followed the American Institute of Certified Public Accountants (AICPA) and Public Accounting Firm for standardizing financial statements.

Dickinson ${ }^{16}$ conducted a study on preparing accounting standards internationally, which is difficult to realize because of complications in terms of implementation, particularly regarding the insurance contracts that do not have default standards; therefore, FASB 133 was issued. The same issue was dealt with by IASC to IAS 39 and followed up by the IASB. In 2001, the IASB proposed a Draft Statement of Principle (DSOP) of insurance contracts.

Arenberg ${ }^{17}$ conducted research on the income earned by insurance companies that tend not to be standardized between one company and the other. This meant the true operating result, particularly in life insurance, can only be determined with reduced accuracy. Scott ${ }^{18}$ also expressed similar findings, except the issue of non-admitted assets. From those issues, some are still relevant, such as the cost of acquisition, non-admitted assets, the valuation reserve, and investment profits and losses. This is related to the certainty of applicable rules and regulations.

Considering the aforementioned issues, in Takaful itself, there are several issues that need to be considered, namely, (a) no gain or loss on underwriting - there needs to be a separation between revenue and expenditure, which is also related to the reserve and contingency; (b) Retakaful (guarantee by the other party) preferably takaful; and (c) a focus on investment, the use of cash on a more realistic basis, which is associated with the distribution of the results. For the shortage of reserve, a qardhul hassan account is not recognized as assets or liabilities ${ }^{19}$.

\section{SFAS No.108}

SFAS No. 108 for Islamic insurance provides a stricter accounting standard. It is associated with aqad governing the insurance itself, for example, the separation of funds between capital owners and participants, tabarru funds, and investments, which is in accordance with Islamic teaching. Therefore, Islamic insurance should be supported by a good information system and clear rules. AAOIFI issued accounting standards for Islamic insurance which was effectively valid since on January 1st, 2000. In Indonesia, the discussion of SFAS for Islamic insurance was started in 2007. This is due to a lot of new Islamic insurance having been established.

Basically, there are not too many differences between the accounting standards for Islamic insurance made by AAOIFI and those proposed by the Institute of Indonesian Accountants (IAI). The difference lies merely in the presentation of the Fund Change Reporting in tabarru. However, when it is compared with conventional accounting standards, there are some differences (see Table 2). 


\begin{tabular}{|c|c|c|c|}
\hline & $\begin{array}{l}\text { SFAS of } \\
\text { Insurance } \\
\text { No. } 36\end{array}$ & $\begin{array}{c}\text { SFAS of } \\
\text { Islamic } \\
\text { insurance No. } \\
108 \text { and } 101 \\
\end{array}$ & $\begin{array}{c}\text { SFAS of } \\
\text { AAOIFI FAS } \\
\text { No. } 12\end{array}$ \\
\hline $\begin{array}{l}\text { Cash flow } \\
\text { statement }\end{array}$ & $\begin{array}{l}\text { Direct and } \\
\text { non-direct } \\
\text { methods }\end{array}$ & Available & Available \\
\hline $\begin{array}{l}\text { Surplus Deficit } \\
\text { Underwriting of } \\
\text { Tabarru Fund }\end{array}$ & $\begin{array}{l}\text { Not } \\
\text { available }\end{array}$ & Available & Available \\
\hline $\begin{array}{l}\text { Changes in } \\
\text { Equity }\end{array}$ & $\begin{array}{l}\text { Not } \\
\text { available }\end{array}$ & Available & Available \\
\hline $\begin{array}{l}\text { Tabarru Fund } \\
\text { Changes }\end{array}$ & $\begin{array}{l}\text { Not } \\
\text { available }\end{array}$ & Available & Not available \\
\hline $\begin{array}{l}\text { Source and } \\
\text { Expenditure of } \\
\text { the Zakat Fund }\end{array}$ & $\begin{array}{l}\text { Not } \\
\text { available }\end{array}$ & Available & $\begin{array}{l}\text { Combined in } \\
\text { Source and } \\
\text { Expenditure } \\
\text { of the } \\
\text { Benevolent } \\
\text { Fund }\end{array}$ \\
\hline $\begin{array}{l}\text { Source and } \\
\text { Expenditure of } \\
\text { the Benevolent } \\
\text { Fund }\end{array}$ & $\begin{array}{l}\text { Not } \\
\text { available }\end{array}$ & Available & $\begin{array}{l}\text { Combined in } \\
\text { Source and } \\
\text { Expenditure of } \\
\text { the Zakat Fund }\end{array}$ \\
\hline $\begin{array}{l}\text { Income } \\
\text { Statement of } \\
\text { Policyholder }\end{array}$ & $\begin{array}{l}\text { Not } \\
\text { available }\end{array}$ & $\begin{array}{l}\text { Available, no } \\
\text { separated }\end{array}$ & Available \\
\hline
\end{tabular}

\section{RESEARCH METHOD}

The method used in this study was an interview with a senior accounts manager of Islamic insurance. This was conducted as not many accountants of Islamic insurance are aware of the issue. The aims of the interview focused on Islamic insurances which have been established, that is, Takaful and Mubarakah insurances, both general insurance and life insurance. In this case, the researcher also was directly involved in the process of observation and the application of SFAS starting from the beginning until the end of 2008.

The difference test was conducted among members of AAOIFI with Indonesia based on Hofstede's classification, which indirectly refers to AAOIFI in preparing accounting standards of Islamic insurance. The test used was the Mann Whitney test. The aim of the test is to examine the differences among AAOIFI members comprising 14 countries, namely, Bahrain, Saudi Arabia, United Arab Emirates, Bangladesh, Turkey, Sudan, Malaysia, Syria, Kuwait, Lebanon, Jordan, Qatar, Iran, and Indonesia. Only eight countries are Arabic countries because Hofstede did not identify every Arab country. These eight countries are Bahrain, Saudi Arabia, United Arab Emirates, Syria, Kuwait, Lebanon, Jordan, and Qatar. Bangladesh and Sudan were not included in the study because they do not exist in Hofstede's weighting. In this case, the theory used was as follows:

"The higher a country ranks in terms of UA and PD and the lower it ranks in terms of IND and MASC then the more likely it is to rank highly in terms of secrecy."

Table.3. The Weighting of Hofstede Component in 5 AAOIFI members ${ }^{23}$

\begin{tabular}{lccccc} 
Component & Arab & Turkey & Iran & Malaysia & Indonesia \\
\hline PD & 80 & 66 & 58 & 104 & 78 \\
IND & 38 & 37 & 41 & 26 & 14 \\
MASC & 52 & 45 & 42 & 50 & 46 \\
UA & 68 & 85 & 59 & 36 & 48 \\
Secrecy & 58 & 69 & 34 & 64 & 66 \\
\hline
\end{tabular}

In this case, the weight of uncertainty avoidance (UA) and the power distance (PD) are summed and then subtracted from individualism (IND) and masculinity (MASC). The total yielded secrecy factor identified the country with the highest degree of secrecy. Indonesia's secrecy level is quite high because Indonesia is reluctant to be transparent compared to countries with a low indicator. However, in Islamic transactions that require 
transparency, the hypothesis becomes invalid because there is an element of the "necessity" to be more transparent.

\section{RESULT AND DISCUSSIONS}

Interviews and analysis in the issuance of SFAS are discussed as follows.

a. It was inevitable that SFAS No. 108 would require the separation of accounting treatment in accordance with the existing aqad. This is quite inconvenient if the clear separation of account is not decided from the beginning. The previously estimated reserve fund must be able to pay for possible claims that would occur. It is related to the limitation that a claim may only be paid from a collection of tabarru. With the new SFAS, tabarru should be separated from other funds, and it should be set at the beginning of the transaction. For Islamic insurance that still has many traditional-based products, this separation is usually quite difficult because there is no clear system in the separation of accounts. For non-traditional products, such as unit-link, the separation of accounts on aqad has been separated by the system. However, this change was in line with the basic regulations of Islamic teaching in Islamic insurance ${ }^{12}$.

b. The separation of account classification in accordance with aqad and regulations would benefit from showing the performance measurement. This is because the adoption of this SFAS will indirectly improve transparency, and the company's survival rate can be predicted appropriately; however, this is difficult for conventional insurance. The religious factor may affect this compliance to standards ${ }^{3}$. Even though the income can be smaller than when using conventional standards, Islamic insurance still upholds the standard, which is stricter than with conventional insurance ${ }^{17,19}$.

c. The most common problem in conventional insurance is the reserve problem for claims. It can be taken to increase the net income by making small reserves. This causes the contract between the participants and insurance to be transactional; besides, the insurance must be able to bear all insurance claims incurred. This does not happen in Islamic insurance, in which the reserve fund for claims has been set at the beginning and subsequently reported. This provides an element of caution. For other reporting, Islamic insurance has been reported voluntarily, although it is not regulated in IAS 36. This result was different from Goodfriend ${ }^{14}$ and Anderson $^{15}$. At an international level, this also differs ${ }^{16,18}$.

The Mann-Whitney difference test for Gray's theory ${ }^{3}$ revealed that the problem of secrecy can be used to see the effect on behavior change in a country. The result in Table 4 below shows an insignificance (above $<0.05)$. This suggests that Indonesia has a higher level of secrecy than AAOIFI member states; however, the difference is statistically not significant. This may indicate that the level of reporting or transparency is relatively low in Indonesia. However, it descriptively shows the opposite situation, i.e., the level of report components for Islamic insurance requires more detail and is dealt with separately. This is certainly not in line with the hypothesis proposed by Gray, as it is not very significant and contradicts Zarzeski's ${ }^{5}$ result, but is consistent with Sudarwan \& Fogarty ${ }^{4}$. This also may be affected by the gap of scoring not being very wide, and Indonesia was in the range.

Table.4. Test Result (Discrimination Test)

\begin{tabular}{lr}
\hline & SECRECY \\
\hline Mann-Whitney U & 1.000 \\
Wilcoxon W & 67.000 \\
$\mathrm{Z}$ & -1.551 \\
\hline
\end{tabular}

\section{CONCLUSION}

In the case of the implementation of this SFAS No. 108 for Islamic insurance, it is a regulatory factor (religion) that requires special accounting treatment. The participants and the insurance companies themselves will feel comfortable and in accordance with the contract agreed at the beginning. The change in accounting standards of Islamic insurance is basically a period of transition from the use of conventional standards to Islamic standards, which is actually not too difficult. In addition, the modern Islamic insurance products require a clear division of accounting accounts.

Statistical testing shows that the differences between the characteristics of Indonesian and of other countries that are AAOIFI members are insignificant. Hofstede gave quite different weights (large) for Indonesia compared to other countries in terms of secrecy; however, the difference is not too great. This indicates that Indonesia should be more closed, but as the religious factor requires transparency then it does not apply under certain conditions.

For further research, a survey of users of financial reports may be undertaken prior to and after the implementation of SFAS 108. This would be an interesting study because such changes can lead to different perspectives. Their responses to changes in accounting treatments are likely to be very transparent in terms of recognition and the ability of Islamic insurance to pay expenses. 


\section{REFERENCES}

[1] G. Hofstede. Culture's consequences: International differences in work related values, Sage Publications, London (1980).

[2] S. J. Gray. Towards a theory of cultural influence on the development of accounting systems internationally. Abacus, 3 (1988) 1-15.

[3] T. S. Doupnik and G. T. Tsakumis. A critical review of tests of Gray's theory of cultural relevance and suggestions for future research, Journal of Accounting Literature, 23 (2004) 1-48.

[4] M. Sudarwan and T. J. Fogarty. Culture and accounting in Indonesia: an empirical examination, The International Journal of Accounting, 31 (1996) 463-481.

[5] M. T. Zarzeski. Spontaneous harmonization effects of culture and market forces on accounting disclosure practices, Accounting Horizons, 10 (1996) 18-37.

[6] B. Jaggi. Impact of culture, market forces, and legal system on financial disclosures, The International Journal of Accounting, 35 (2000) 495-519.

[7] T. S. Doupnik and M. Richter. The impact of culture on the interpretation of 'in context' verbal probability expressions, Journal of International Accounting Research, 3(1) (2004) 1-20.

[8] C. B. Roberts and S. B. Salter. Attitudes towards uniform accounting: cultural or economic phenomena?, Journal of International Financial Management and Accounting, 10 (1999) 121-142.

[9] S. Chanchani and MacGregor. A synthesis of cultural studies in accounting, Journal of Accounting Literature, 18 (1999) 1-30.

[10] A. Smith. Testing the stability of the global concept of culture in an accounting context, Accounting Enquiries, 11(2) (2002) $227-249$.

[11] I. Noravesh, Z. D. Dilami, and M. S. Bazaz. The impact of culture on accounting: does Gray's model apply to Iran?,Review of Accounting \& Finance, 6(3) (2007).

[12] A. Saha, A. K. Ganguli, and S. A. Banerjee. Primer on the evolution of Takaful, Tata Consultancy Services, (2008).

[13] PricewaterhouseCoopers. Takaful: growth opportunities in a dynamic market, (2008).

[14] H. E. Goodfriend. Adjusting life insurance company earnings to conform with Generally Accepted Accounting Principles, Financial Analyst Journal, 26(3) (1970) 51-58.

[15] J. J. Anderson. Financial accounting practices of property and liability insurance companies, The Journal of Risk and Insurance, 39(2) (1972) 201-213.

[16] G. Dickinson. The search for International Accounting Standard for insurance, Special Report to the Task Force on Accountancy of the Geneva Association, (2003).

[17] J. T. Arenberg. Life insurance accounting and reporting and the independent public accountant, The Journal of Risk and Insurance, 37(2) (1970) 253-262.

[18] D. G. Scott. Life insurance and accounting statements, The Journal of Risk and Insurance, 37(3) (1970) 447-450.

[19] O. Morshed. Takaful accounting, Sidat Hyder Morshed Associates (Pvt) Ltd, (2003).

[20] Accounting \& Auditing Organization for Islamic Financial Institutions (AAOIFI). Accounting, Auditing \& Governance Standards (for Islamic Financial Institutions), AAOIFI, Manama (2008).

[21] Ikatan Akuntan Indonesia (IAI). Pernyataan Standar Akuntansi Keuangan No. 36, PT Salemba Empat, Jakarta (2007).

[22] Ikatan Akuntan Indonesia (IAI). Pernyataan Standar Akuntansi Keuangan No. 108, PT Salemba Empat, Jakarta (2009).

[23] G. Hofstede. Geert. Hofstede scores, www.geert-hofstede.com (2010). 